\title{
A TOTALLY NONAPOSYNDETIC, COMPACT, HAUSDORFF SPACE WITH NO CUT POINT
}

\author{
EDWARD E. GRACE ${ }^{1}$
}

This paper gives a negative answer to the following question posed by A. D. Wallace. Does each totally nonaposyndetic, ${ }^{2}$ bicompact, connected, Hausdorff space contain a weak cut point? ${ }^{3}$ Conditions which assure the existence of weak cut points in totally nonaposyndetic continua are given in [1] and [2].

Example 1 gives a totally disconnected, perfect, first-countable, bicompact, Hausdorff space $K$, of cardinal $c$, such that (the closure of) each subset of cardinal less than $c$ is nowhere dense. The space $K$ will be used in describing the main example.

EXAMPLE 1. Let $I$ be the space of all functions $f$ from the natural numbers into $[0,1]$. Let $I$ have the order topology relative to the lexicographical order. ${ }^{4}$ Let $K$ be the set of all $f$ in $I$ such that, if $f(i)=\frac{1}{2}$, then either $f(j)=0$, for $j>i$, or $f(j)=1$, for $j>i$.

EXAMPLE 2. Let $z$ be the first ordinal that is preceded by $c$ ordinals. Let $S$ consist of four long lines (of "length" $c$ ), put together as in Figure 1, with the connecting points $a_{z}$ and $a_{z}^{\prime}$.

Let $K^{\prime}$ be a copy of $K$ and, for each point or subset $A$ of $K$, let $A^{\prime}$ denote the corresponding point or subset of $K^{\prime}$. Let $k_{1}, k_{2}, \cdots$, $k_{x}, \cdots$, for $x<z$, be a most economical well-ordering of $K$. Let $K^{\prime \prime}$ be the union of $K$ and $K^{\prime}$ with $k_{1}$ and $k_{1}^{\prime}$ identified. For $y<z$, let $K_{y}$ be the closure of $\left\{k_{x} \mid x \leqq y\right\}$. Let $K_{z}=K$.

Let $H$ be the decomposition space of $K^{\prime \prime} \times S$, the nondegenerate elements of which are $\left\{\left(k, a_{y}\right) \mid k \in K_{y}\right\}$ and $\left\{\left(k^{\prime}, a_{y}^{\prime}\right) \mid k^{\prime} \in K_{y}^{\prime}\right\}$, for $y \leqq z$.

Figure 2 will aid in visualizing $H$. It does not indicate the identifications that prevent cutting by the vertices. The intervals in the figure represent copies of $S$.

$H$ is a totally nonaposyndetic, bicompact, Hausdorff space that

Presented to the Society, April 14, 1962; received by the editors February 13, 1962 and, in revised form, January 4, 1963.

1 This work was completed while the author was on leave from Emory University as an N.S.F. Science Faculty Fellow at the University of Wisconsin.

${ }^{2}$ A continuum $T$ is totally nonaposyndetic if it is nonaposyndetic at each point, i.e., if for each point $x$ in $T$ there is a point $y$ in $T$ such that each subcontinuum of $T$ that contains $x$ in its interior also contains $y$.

${ }^{3}$ The author wishes to thank Professor F. Burton Jones for calling this question to his attention.

${ }^{4} g<f$ if, for some $i, g(i)<f(i)$ and $g(j)=f(j)$ for $j<i$. 


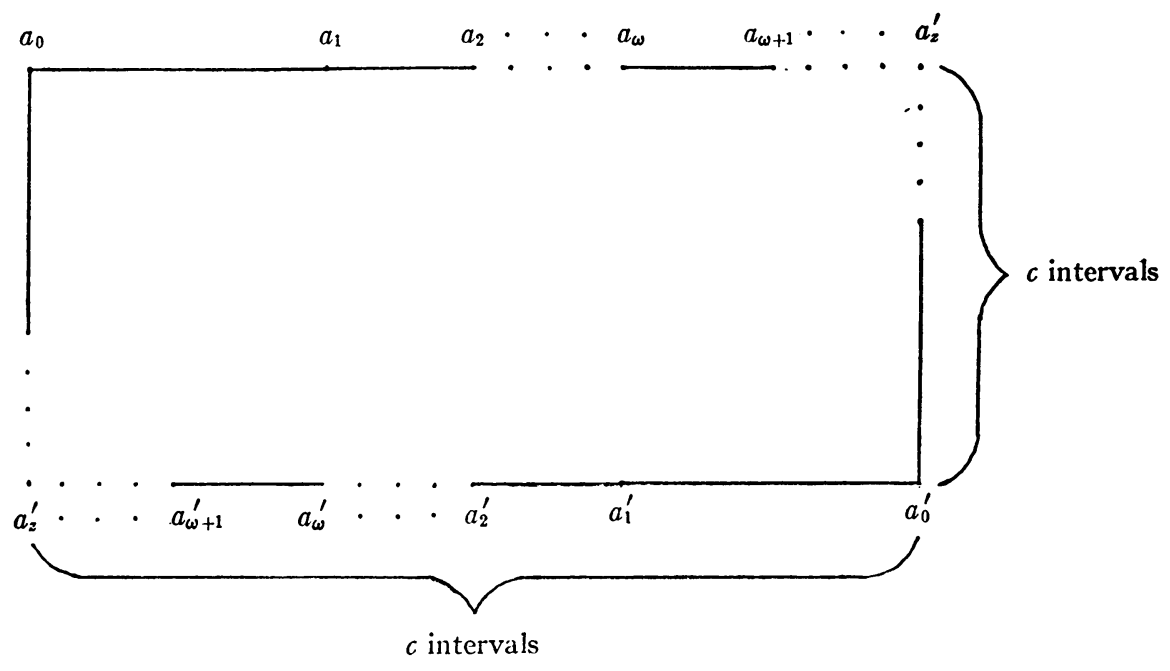

FIGURE 1

contains no weak cut point. $H$ satisfies the first axiom of countability at each point of a dense open set.

The total nonaposyndesis of $H$ can be seen as follows. Let $v$ be the vertex $\left\{\left(k, a_{z}\right) \mid k \in K_{z}\right\}$ of $H$. If $p \neq v$ is a point of the part of $H$

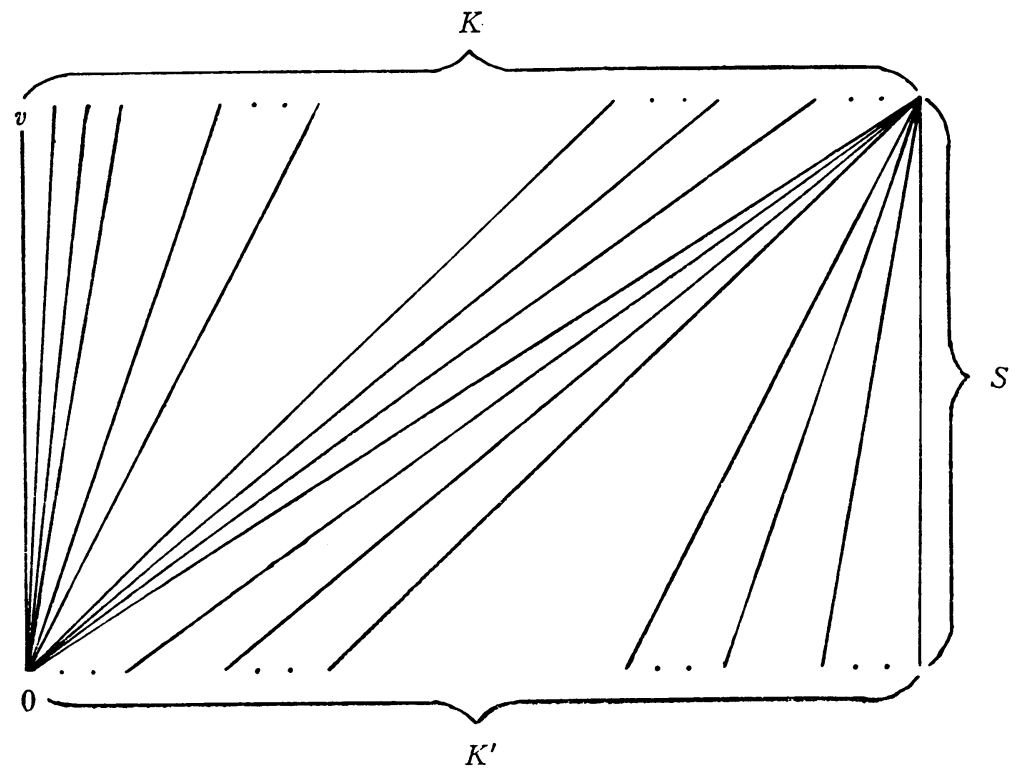

FIGURE 2 
that comes from $K \times S$ and $D$ is an open set in $H-p$ containing $v$, then $p$ is not an interior point of the $p$-component of $H-D$. This follows from the fact that $K_{y}$ is nowhere dense in $K$, for $y<z$. It implies that $H$ is nonaposyndetic at $p$ with respect to $v$. As a consequence of this and the corresponding fact about the part of $H$ that comes from $K^{\prime} \times S$, the continuum $H$ is totally nonaposyndetic.

Question. Does each totally nonaposyndetic, bicompact, connected, Hausdorff space, that satisfies the first axiom of countability, contain a weak cut point?

\section{REFERENCES}

1. E. E. Grace, Cut sets in totally nonaposyndetic continua, Proc. Amer. Math. Soc. 9 (1958), 98-104.

2. F. B. Jones, Concerning non-aposyndetic continua, Amer. J. Math. 70 (1948), 403-413.

EMORY UNIVERSITY AND

UNIVERSITY OF WISCONSIN 